\title{
LEUKEMIA; \\ DIFFERENTIAL EXPRESSION OF PROPHETIC VARIABLES OF MEDICAL IMPORTANCE AND THEIR POTENTIAL ROLE IN THE PATHOGENESIS
}

\author{
1. MBBS, M. Phil \\ Associate Professor, \\ Department of Biochemistry, \\ Faisalabad Medical University, \\ Faisalabad-Pakistan \\ 2. PhD \\ Institute of Molecular Biology \\ and Biotechnology (IMBB), \\ The University of Lahore, Pakistan \\ 3. MBBS, M. Phil \\ Associate Professor, \\ Independent Medical College, \\ Faisalabad-Pakistan \\ 4. M. Phil \\ Institute of Molecular Biology \\ and Biotechnology (IMBB), \\ The University of Lahore, Pakistan. \\ 5. M. Phil \\ Institute of Molecular Biology \\ and Biotechnology (IMBB), \\ The University of Lahore, Pakistan.
}

\section{Correspondence Address:}

Arif Malik

University of Lahore,

$1 \mathrm{KM}$ Defense Road,

Off Raiwind Road, Lahore

arifuaf@yahoo.com

Article received on:

29/07/2017

Accepted for publication:

05/09/2017

Received after proof reading:

06/10/2017
Muhammad Shahzad Farooq ${ }^{1}$, Arif Malik ${ }^{2}$, Bushra Shaheen ${ }^{3}$, Qurat-ul-Ain ${ }^{4}$, Sulayman Waquar ${ }^{5}$

ABSTRACT... Background: Leukemia is a hematological malignancy i.e. that arises in the blood progenitor cells. It is a tumor of white blood cells which is characterized by uncontrolled proliferation of immature hematopoietic WBCs in bone marrow. Leukemia is of two types myeloid and lymphoid and two subtypes acute and chronic. Acute lymphoid leukemia is most common in children. There are certain risk factors associated with leukemia like ionizing radiations, genetic polymorphisms. Drug resistance in leukemia is linked with polymorphisms for gene coding enzymatic antioxidants. Multiple circulating biochemical markers depict pathogenesis of leukemia. Elevated reactive oxygen species and decreased antioxidant elements reveal occurrence of various malignancies. Study Design: Case Control Study. Setting: Study was conducted at Institute of Molecular Biology and Biotechnology (IMBB), University of Lahore. Period of Study: One year. Materials and Methods: Blood samples of 270 leukemic patients between the age of 30-55 were collected from PINUM and Allied Hospital, Faisalabad. While the samples of 100 individuals were served as a control. Levels of both enzymatic and nonenzymatic antioxidant such as CAT, GSH, SOD, GPx and GRx, vitamin A, C and E and levels of MDA were determined spectrophotometrically. While the concentration of IL6, AOPPS, AGEs, TNF- $\alpha$, MMP9 and Isoprostanes were measured by using commercially available Elisa kits. Results: This research work was conducted on a total of 100 control subjects and 270 leukemic patients and the results were described on mean values. Many circulating biochemical stress markers, antioxidants and vitamins were investigated. All enzymatic and non-enzymatic antioxidants, vitamins were decreased in leukemic individuals while markers which showed high oxidative stress like MDA, IL6, AOPPS, TNF- $\alpha$ and MMP9 were elevated in leukemic patients. Conclusion: It is concluded from this study that low levels of antioxidants and high levels of oxidative stress depict the pathological state of leukemia and defected cell proliferation and growth. Continuous evaluation of antioxidant levels during leukemia can serve as a way of better prognosis and treatment of leukemia.

Key words: $\quad$ Leukemia, ALL (acute lymphoblastic leukemia), oxidative stress, Antioxidants.

Article Citation: Farooq MS, Malik A. Shaheen B, Qurat-ul-Ain, Waquar S. Leukemia; differential expression of prophetic variables of medical importance and their potential role in the pathogenesis. Professional Med J 2017;24(10):15191526. DOI:10.17957/TPMJ/17.4198

\section{INTRODUCTION}

Hematological malignancies are such cancers that initiate in the blood progenitor cells i.e. cells of bone marrow or immune system. The malignances of red blood cells include anemia and polycythemia while the Tumors of white blood cells include leukocytosis, leukopenia, leukemia, lymphoma and multiple lymphomas. Leukemia can be characterized as a disorder which is caused due to the uncontrolled proliferation of immature hematopoietic white blood cells in bone marrow (BM). This word leukemia was first coined in mid-19th century by Greek word 'leukos' 'white' + 'haima' 'blood'. Hematological malignancies are caused by certain disturbances in Extracellular Matrix (ECM). ${ }^{1}$

Leukemia is considered as a neoplastic disorder which is susceptible to antioxidant enzymes and some important essential factors alteration. ${ }^{2}$ ROS (Reactive oxygen species) are diverse collection of compounds which are produced by the mature myeloid cell lines in an innate response. Biochemical production of ROS initiates when an electron escapes from complex 1 or 3 it may react with molecular oxygen. Reactive oxygen 
produced during cellular metabolism can be converted to hydrogen peroxide $\left(\mathrm{H}_{2} \mathrm{O}_{2}\right)$. This $\mathrm{H}_{2} \mathrm{O}_{2}$ if accumulated in body is highly potent and needs to me promptly removed from the body. This action is carried out by antioxidants. Imbalance between generation of ROS and compromised function of antioxidant defense system results in oxidative stress. Oxidative stress plays an important role in pathophysiology of cancer and many other diseases. These ROS target lipids, proteins and nucleic acids in living cells diminishing the normal cell biology and structure.DNA damage is not repaired properly in the oxidative stress which leads to mutagenesis. ${ }^{3}$ Oxidative stress processes may alter the efficacy of a drug therapy, adverse effects of chemotherapeutic medicines and also the apoptotic processes of malignant cells. ROS if accumulated at higher levels in the cells cause DNA damage and cellular senescence i.e. a state of irreparable growth detention, which can be initiated by the excessive proliferation and oncogenic activation and cell damage through the oxidative stress. ${ }^{4}$

These mischievous activities of ROS have led to the development of antioxidant defense mechanism which targets both production and harmful effects of reactive oxygen species. Antioxidants are important to regulate the oxidative stress which is the important defense mechanism in normal conditions. ROS has an imperative part in cancer origination and development of certain evidence, because Reactive oxygen species initiate cell proliferation and promotes genetic instability. Different research studies show that anti-oxidant enzyme such as superoxide dismutase (SOD) levels are raised in cancer patients than the normal person's SOD levels. ${ }^{5}$ Antioxidants like glutathione have an important role to have hold on oxidative stress, Glutathione (GSH) is involved in some other activities like cell differentiation, proliferation and cellular apoptosis. Glutathione deficiency causes oxidative stress, aging and pathogenesis in the form of different diseases like cancer. GSH contents in cancer cells are responsible for multidrug resistance and radiation resistance. GSH is important because of its function to detoxify the carcinogens, they are elevated in cancers and in tumors which in- turn causes the resistance to chemotherapy and radiations. ${ }^{6}$

The leukemic cells that are sensitive to etoposide (a chemotherapeutic drug) have high levels of glutathione. Malondialdehyde (MDA) is a specified marker for the indication of defect in lipid peroxidation. As it is a byproduct of beta oxidation of lipids, increase levels of MDA indicate oxidative stress in body. AOPPS (advanced oxidation protein products) are the proteins that are highly susceptible to reactive oxygen species; they are measured to observe critically ill and cancer patients. Oxidation of amino acid residues like tyrosine which form the dityrosine, protein aggregation, cross linking is one of the damage caused by the ROS. The detected changes in levels of MDA and DNA damage were significantly elevated in chronic lymphocytic leukemia. Urinary 8-hydroxydeoxyguanosine (reliable prognostic marker) and clinical characteristics of hematological disorders including non-Hodgkin's lymphoma are correlated. Vitamin $\mathrm{E}$ that serves as a significant antioxidant is present in lower concentrations in patients with chronic myeloid leukemia, these levels raised after the treatment. This shows fall in oxidative stress due to rise in tumor load. Natural killer cells are supposed to play an important role in surveillance of human tumors. They recognize malignant cells when there is an active equilibrium between opposed functions of suppression and initiation receptors of NK cells. Acute leukemia is generally considered as the rapidly progressive disorder with a deprived prognosis. In case of AML the levels of NK cells are profoundly reduced and some other activator receptors levels are drastically down regulated resulting low NK-cells cytotoxicity against the autologous leukemic cells. ${ }^{7}$ Synthetic or naturally derived compounds are supposed to play role in cancer chemoprevention if administered before occurrence of disease. Many agents are known to be effective against chemical carcinogenesis and cancer progression. Multiple characteristics of these carcinogenic processes can be altered to suppress or delay cancer progression. These potent compounds are being identified by many practical assays. Several plant derived compounds have gained significant attention 
for their anti-cancer activity against a variety of malignancies including leukemia. Different plants derived compounds (use in combination with 2 or three and more) are used due to their anti-cancer activity. Most of the chemotherapeutic agents are pro-oxidants. Radiotherapy, chemotherapy induce cancer cell regression, low intracellular peroxide level hence apoptosis is initiated in tumor cells by the oxidant prompted molecular pathways. The induction of intracellular reactive oxygen species generation and the decrease in mitochondrial membrane potential, and instigation of caspases 3 these all factors are inter-related with each other. ${ }^{8}$ Certain risk factors which are associated with the acute lymphocytic leukemia and acute myeloblastic leukemia which includes environmental risk factors like ionizing radiations are significantly linked to the acute lymphocytic leukemia and acute myeloblastic leukemia. ${ }^{9}$ In different research studies different factors are highlighted which are interactive to the physiological systems directly or indirectly causing disrupted mechanism. But a lot of genetic factors are also involved. Hypothetically drug resistance might be regulated by functional polymorphisms in the genes coding for antioxidant enzymes includes.

Manganese superoxide (MnSOD), catalase (CAT) and glutathione peroxide (GPX).${ }^{10}$ Matrix metalloproteinases (MMPs) and their inhibitors tend to play important role in tumor invasion and progression. MMP 2 and 9 produced by lymphocytes have major observed roles in this regard. In leukemic conditions levels of MMPs are supposed to be lower as tissue inhibitors of matrix metalloproteinases are elevated in a number of studies. Elevated MMP9 levels depicted advanced disease stage and poor patient survival rate. ${ }^{11}$

\section{MATERIALS AND METHODS}

Present study was designed to estimate the levels of oxidants and antioxidants in leukemic patients. The study was based on subgroups of 270 leukemic patients and 100 controls. leukemic subtypes (AML $n=97, A L L-B n=99, A M L-T n=74$ ) and subgroup of patients according of one, two, three, four, five and six years of therapy duration respectively. The subjects in 1 year therapy were
25, 30 in two year, 6 in three year, 98 in four year, 87 in five year while 24 in six year of therapy duration as shown in the Table-l. $5.0 \mathrm{ml}$ blood sample was taken from vein. Blood samples were collected into EDTA tubes, centrifuged at 4000 rpm for 10 minutes and serum was separated. All experimental protocols were approved by the Research Ethical Committee of Institute of Molecular Biology and Biotechnology (IMBB).

\begin{tabular}{|l|c|}
\hline \multicolumn{1}{|c|}{ Mean age } & $\mathbf{n}$ \\
\hline $18-35$ & 100 \\
$36-50$ & 140 \\
Above 50 & 30 \\
\hline Family history of leukemia patients & $\mathbf{n}$ \\
\hline Don't know & 105 \\
No & 70 \\
Yes & 95 \\
\hline Smokers & $\mathbf{n}$ \\
\hline No & 175 \\
Yes & 95 \\
\hline Medication & $\mathbf{n}$ \\
\hline No & 190 \\
Yes & 80 \\
\hline Occupation & $\mathbf{n}$ \\
\hline Unskilled & 100 \\
\hline Skilled & 110 \\
\hline Professional & 60 \\
\hline Table-l. Demographic distribution in the leukemic \\
\hline
\end{tabular}

\section{BIOCHEMICAL ANALYSIS}

SOD was measured by spectrophotometric method of Kakkar et al., ${ }^{12} 100 \mu \mathrm{l}$ serum was taken in test tube and then $1.2 \mathrm{ml}$ of $0.052 \mathrm{M}$ sodium phosphate buffer, $100 \mu$ l of phenazine methosulphate $(186 \mu \mathrm{m}), 300 \mu \mathrm{l}$ of nitro blue tetrazolium $(300 \mu \mathrm{m})$ and $200 \mu \mathrm{l}$ of $\mathrm{NADH}(750 \mu \mathrm{m})$ was added. Reaction was started when $\mathrm{NADH}$ added. Then incubated at $30^{\circ} \mathrm{C}$ for $90 \mathrm{sec}, 100 \mu \mathrm{l}$ of glacial acetic acid and $4.0 \mathrm{ml}$ of $\mathrm{n}$-butanol was added. The mixture was allowed to stand for $10 \mathrm{~min}$, centrifuged and butanol layer was separated. The color intensity of the chromogen in butanol layer was measured at $560 \mathrm{~nm}$ against n-butanol and concentration of SOD was expressed as units/g.MDA was measured by spectrophotometric method of Okawa et al. ${ }^{13}$ In each test tube, $200 \mu \mathrm{l}$ sample, $200 \mu \mathrm{l}$ of $8.1 \%$ sodium dodecyl sulfate (SDS), $1.5 \mathrm{~mL}$ of 
$20 \%$ acetic acid solution $(\mathrm{pH} 3.5)$ and $1.5 \mathrm{~mL}$ of $0.8 \%$ TBA. The mixture was made up to $4.0 \mathrm{~mL}$ with distilled water and heated in a water bath at $90 \circ \mathrm{C}$ for $60 \mathrm{~min}$. Then $5.0 \mathrm{~mL}$ of $\mathrm{n}$-butanol were added and shaken vigorously and centrifuged at $4000 \mathrm{rpm}$ for 10 minute upper butanol layer was taken and the upper layer was taken and its absorbance was taken at $532 \mathrm{~nm}$ was read. CAT was measured by spectrophotometric method of Aebi. ${ }^{14}$ In each test tube, $100 \mu$ l serum, $1.9 \mathrm{~mL}$ of $50 \mathrm{mM}$ phosphate buffer ( $\mathrm{pH} 7.0)$. Reaction was started when $1.0 \mathrm{~mL}$ of freshly prepared $30 \mathrm{mM}$ $\mathrm{H}_{2} \mathrm{O}_{2}$ added. The rate of decomposition of $\mathrm{H}_{2} \mathrm{O}_{2}$ was measured spectrophotometrically at 240nm. Reduced glutathione was determined by the method of Moron et al. ${ }^{15}$ Reduced glutathione react with DTNB $(5,5$ '-dithiobis nitro benzoic acid) which further will produce a yellow colored product that absorbs at $412 \mathrm{~nm}$. Vitamin C estimated by Mohammad. ${ }^{16} 50 \mu \mathrm{L}$ sample and $20 \%$ of TCA was added in each test tube and then stirred to obtain a very fine suspension and then allowed to stand for 5 minute and centrifuge it at $10000 \mathrm{rpm}$ for 5 minutes. 3ml 2\% CMC (carboxy methyl cellulose) and $600 \mu \mathrm{L}$ of $2 \%$ Selenium dioxide was added in $300 \mu \mathrm{L}$ of supernatant and volume was taken up by addition of $7.5 \mathrm{ml}$ distilled water into test tube. Absorbance was taken at $380 \mathrm{~nm}$. Vitamin $\mathrm{E}$ is estimated by Kayden et al. Advanced oxidation protein products (AOPPs) were estimated according to the method of WitkoSarsat et al. ${ }^{17}$ While NO was determine by using grease's reagent. ${ }^{18}$ Glutathione peroxidase was estimated by the method of spectrophotometer with the help of buffer/ enzyme reagent. Glutathione reductase was determined by using method of David and Richard. ${ }^{19}$ Levels of IL-6 and TNF-a were estimated by using commercially available Elisa Kit.

\section{RESULTS}

The data demonstrated in the Table-II represents the clear image concerning the concentration of oxidative stress markers in leukemia patients. Levels of oxidants and anti-oxidants were differed significantly in both groups $(P<0.05)$. Mean age of the subjects was ranged between 30-55 years. Significantly lowered serum concentrations of SOD, catalase and GSH were recorded
$(0.09 \pm 0.091,2.25 \pm 1.18$ and $4.35 \pm 1.620)$ as compared to healthy subjects $(0.49 \pm 0.14$, $3.95 \pm 1.18$ and $9.79 \pm 1.22)$. Higher levels of GGT were recorded in leukemic patients $(58.75 \pm 8.56)$ in comparison to control (43.12 \pm 6.82$)$. Vitamin $A, C$ and $E$ were also decreased in leukemic patients (424.48 $\pm 94.04, \quad 0.36 \pm 0.23$ and $0.25 \pm 0.09$ ) relative to the healthy individuals (615.92 $\pm 44.52,0.56 \pm 0.088$ and $0.29 \pm 0.052$ ). Total antioxidant status (TAS) in leukemia patients was lower $(1.38 \pm 0.17)$ than the healthy controls (1.54 \pm 0.15$)$. Levels of IL-6, TNF-a in leukemia patients were elevated $(6.73 \pm 0.84$ and $31.67 \pm 4.47)$ in comparison with healthy subjects $(5.64 \pm 0.51$ and $29.90 \pm 1.142)$. As far as the levels of AOPPs, AGEs, MDA and isoprostanes were concerned, a significant increase was recorded in leukemic patients $(1.46 \pm 1.10$, $2.77 \pm 0.29,3.80 \pm 1.14$ and $365.42 \pm 186.78)$ in contrast to control $(0.845 \pm 0.043,2.56 \pm 0.103$, $1.43 \pm 0.36$ and $69.91 \pm 11.20)$. The results of the present study depicted comparatively high total thiol concentration in leukemic patients $(0.58 \pm 0.158)$ as compared to control. Levels of neopterin (8.55 \pm 7.760 Vs control 5.82 \pm 4.97 ), zinc $(0.62 \pm 0.35$ Vs control $0.81 \pm 0.132)$, copper $(1.05 \pm 0.021$ Vs control $0.68 \pm 0.144)$, serum Fe (138.16 \pm 19.06 Vs control $85.28 \pm 3.26)$, NO (57.70 \pm 8.99 Vs control 19.42 \pm 1.42$)$, protein carbonyl (5.63 $\pm 0.96 \mathrm{Vs}$ control $2.24 \pm 0.95)$, serum ferritin (1.86.29 \pm 69.14 Vs control 105.57 \pm 1.95$)$, urinary neopterin level (133.85 \pm 8.22 Vs control $9.046 \pm 8.83)$ and GSH-Px (4.39 \pm 1.59 Vs control $1.47 \pm 0.22)$ were higher significantly.

\section{DISCUSSION}

This study was based on the mean values of normal and leukemic subjects and their comparison that which parameter increases or decreases during leukemic state hence providing us with potent markers for prognosis of leukemia. Lose of capacity of hematopoietic stem cells to differentiate into mature blood cells are termed as leukemia. ${ }^{20} \mathrm{As}$ oxidative stress is characterized by imbalance between reactive oxygen species and antioxidants. ${ }^{21}$ Various clinical and experimental studies revealed the involvement of free radicals in biochemical mechanisms involved in various hematological disorders including leukemia. ${ }^{22}$ 


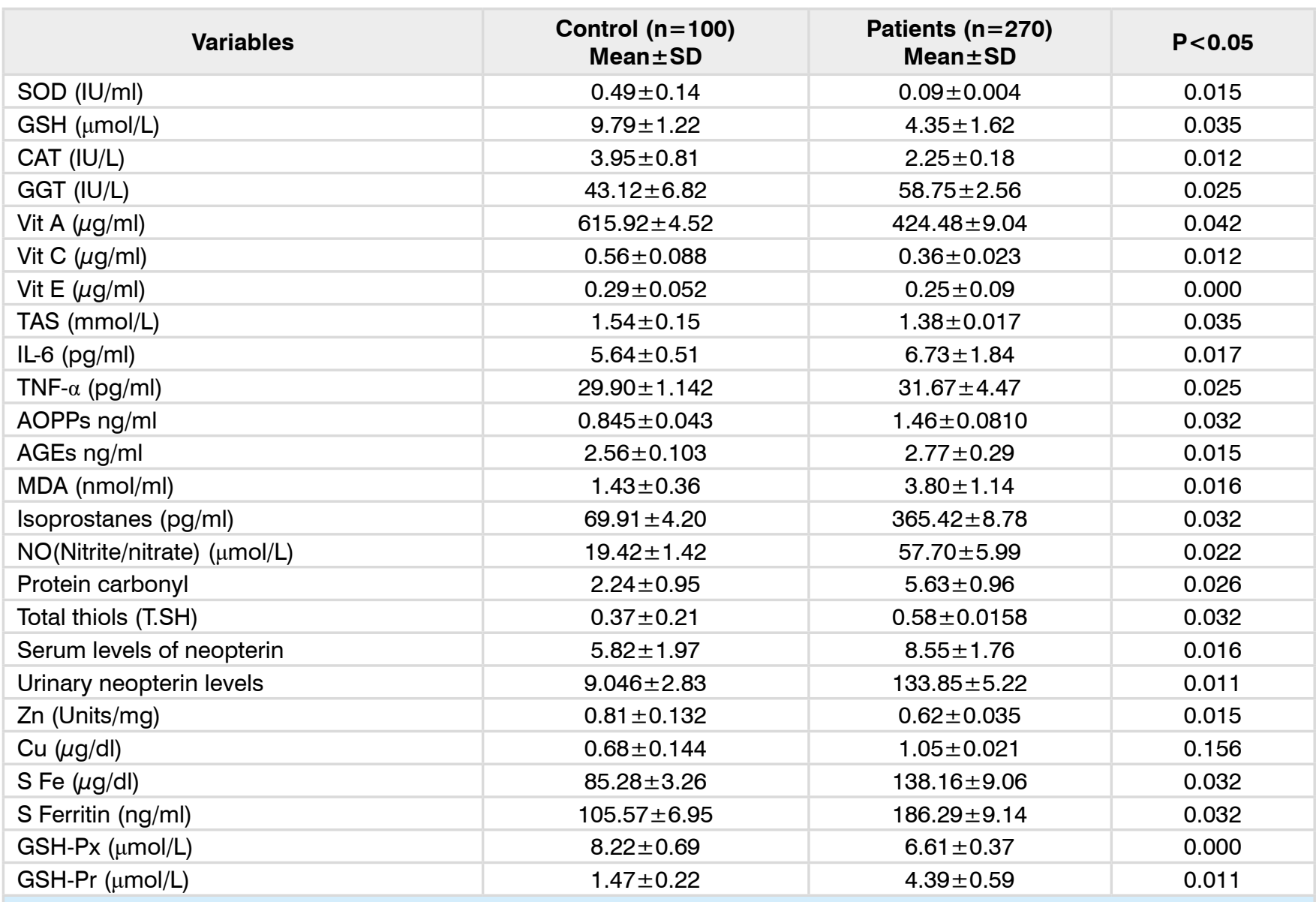

Table-ll. Estimation of different variables in patients suffering from leukemia

Increased amount of reactive oxygen species are produced in leukemia patients as compared to non-leukemia subjects concluded by Al-Gayyar et al. (2007). ${ }^{23}$ Another study found that in acute lymphocytic leukemia patients, plasma level of GSH-Px and SOD were lowered significantly. ${ }^{24}$

Higher concentration of MDA and protein carbonylation was observed in patients suffering from acute lymphocytic leukemia then in control..$^{25}$ Impaired antioxidant status was observed in children suffering with acute lymphocytic leukemia. ${ }^{26}$ MDA levels serve as a prognostic marker to determine disease progress. High protein carbonyl and MDA levels show impaired antioxidants and promising ROS levels, which are also characteristics of disease relapse. ${ }^{27}$ In the present study our results depicted high MDA levels as compared to normal controls. Enzymatic antioxidants like SOD, catalase was all observed to be decreased in leukemic state.
Total antioxidant status was also known to be decreased. These products are involved in the pathogenesis of cancer.ROS accumulation results in the damage of lipids, DNA and protein that results in the formation of various protein products. ${ }^{28}$ Decreased antioxidant status and increased oxidative stress results in the formation of advanced glycation end product AGEs, advanced oxidation protein products (AOPPs) and S-nitrosylated proteins in patients suffering from leukemia. ${ }^{29}$

Carbonylation or non-enzymatic oxidation of proteins results in the formation of protein carbonyls (PC) that indicates free radicals production in cells.Protein carbonylation cause dysfunctioning of proteins that is an indicator of severe oxidative stress. ${ }^{30}$ Significantly increased serum level of protein carbonyl was observed in chronic myeloid leukemia in both chronic and accelerated phase in comparison with healthy 
subjects. ${ }^{31}$ Current findings are in agreement with various other observations that indicated increased level of protein carbonyl and decreased total thiols in the patients suffering with acute myeloid leukemia. ${ }^{32,33}$ While same observations were reported in patients suffering with other malignancies such as lung and bladder cancers and Hodgkin's lymphoma etc. ${ }^{34,35}$ Furthermore, depletion of T.SH and GSH was observed in patients suffering from different phases of chronic myeloid leukemia that indicated increased production of ROS in hematopoietic cells. Various findings demonstrated that ROS plays a major role in metastasis of tumor cells. ROS oxidizes protein tyrosine phosphatase (PTPs) and protein kinase $C(P K C)$ that cause tumor cell invasion. BCR-ABL fusion in Philadelphia chromosomes produce a fusion protein that cause increased ROS production in hematopoietic stem cells in leukemia patients. ${ }^{36}$ On the other hand, BCR$A B L$ fusion protein cause perturbation in the functioning of stem cells and mechanism involved increase tyrosine kinase activity. ${ }^{37} \mathrm{~A}$ recent study demonstrated that ROS stimulated by BCR-ABL kinase cause damage to DNA that results in the mutations and progression of chronic myeloid leukemia. BCR-ABL fusion protein has been involved into various cytogenetic alterations, increased free radical production, genomic instability and disease progression. These alterations create an environment that is more favorable for mutations, macromolecule damage and metastasis in chronic myeloid leukemia. ${ }^{38}$ The antioxidant defense system comprise of enzymatic antioxidants like SOD, CAT, GPx which have the ability to degrade the superoxide into hydrogen peroxide and then into water. ${ }^{39}$ Examined the functioning of SOD, CAT, GPx, oxidized and reduced GSH, MDA and 8-oxo-2 deoxyguanosine in patients of chronic myeloid leukemia. SOD and catalase activity was recorded to be decreased while glutathione peroxidase activity increased. Reduced glutathione concentration also increased while oxidized GSH concentration remained constant. Hence a reduced GSSG/GSH ratio was observed. MDA and the 8-oxo-dG were also increased in chronic lymphoid leukemia (CLL) patients. The concentration of these also increased as the duration of disease. The results depicted a high oxidative stress condition in chronic lymphoid leukemia. ${ }^{40}$

Our findings indicated that AOPPs, AFP, AGE, TNF alpha, IL6, MMP9 and protein carbonyl are all disease progression markers and are recorded to be elevated in leukemic condition. Total thiol play a significant role against ROS, and are found in oxidized and reduced glutathione form. Elevated levels of total thiols were observed in diseased patients. Isoprostanes which are markers of inflammation and lipid peroxidation were also exceedingly elevated in leukemic state. Increased expression of Matrix metalloproteinase 2 was detected in patients of acute myeloid leukemia and these elevated levels were responsible for the invasion features of anti-drug AML cells. Migration and degradation of acute myeloid leukemic cells is dependent on leukemia cellwhich is formed due to binding of MMP9 to CD18 cells. ${ }^{41}$

\section{CONCLUSION}

In summary, the results of present study support the concept that increased oxidative stress and reduced antioxidant capacity cause non-specific damage to biomolecules in hematopoietic cells as well as to other cells. Persistent increase in free radical induced lipid peroxidation and protein carbonylation and depletion of antioxidant defense results in progression of cancer in leukemia patients.

Copyright (C) 05 Sep, 2017.

\section{REFERENCES}

1. $\mathrm{Yu}$ XF, and Han ZC. Matrix metalloproteinase in bone marrow: roles of gelatinases in physiological hematopoiesis and hematopoietic malignancies. Histology and histopathology. 2006; 21:519-531.

2. Zuo XL, Chen JM, Zhou X, Li XZ and Mei GY. Levels of selenium, zinc, copper, and antioxidant enzyme activity in patients with leukemia. Biological trace element research. 2006; 114:41-53.

3. Kryston TB, Georgiev AB, Pissis P and Georgakilas AG. Role of oxidative stress and DNA damage in human carcinogenesis. Mutation research. 2011; 711:193201.

4. XiaoY, Zou P, Wang J, Song H, Zou J and Liu L. Lower phosphorylation of p38 MAPK blocks the oxidative stress-induced senescence in myeloid leukemic 
CD34 (+) CD38 (-) cells. Journal of Huazhong University of Science and Technology Medical sciences. 2012; 32:328-333.

5. Ahmad R, Singh R, Tripathi AK, and Singh RK. Leukocyte superoxide dismutase activity in patients with chronic myeloid leukemia. Revista brasileira de hematologia e hemoterapia.2012; 34:394-395.

6. Abdalla MY. Glutathione as Potential Target for Cancer Therapy; More or Less is good? (Mini-Review). Jordan Journal of Biological Sciences. 2011; 4:119-124.

7. Choi WY, Choi BT, Lee WH and Choi YH. Sulforaphane generates reactive oxygen species leading to mitochondrial perturbation for apoptosis in human leukemia U937 cells. Biomedicine \& pharmacotherapy. 2008; 62:637-644.

8. Hole PS, Darley $\mathrm{RL}$ and Tonks A. Do reactive oxygen species play a role in myeloid leukemias? Blood. 2011; 117:5816-5826.

9. Charalambous $A$ and Vasileiou P. Risk factors for childhood leukemia: a comprehensive literature review. Health science journal. 2012; 6:432-468.

10. Koistinen P, Ruuska S, Saily M, Kakko S, Siitonen P, Siitonen T, Savolainen MJ, Kinnula VL and Savolainen ER. An association between manganese superoxide dismutase polymorphism and outcome of chemotherapy in acute myeloid leukemia. Haematologica. 2006; 91:829-832.

11. Ries C, Loher F, Zhang C, Ismair MG, and Petrides PE. Matrix metalloproteinases production by bone marrow mononuclear cells from normal individuals and patients with acute and chronic leukemia or myelodysplastic syndromes. Clinical cancer research. 1999; 5:1115-1124.

12. Kakkar PB, Das $P$, Vishwanathan PN. A modified spectrophotometer assay of superoxide dismutase. Ind J Biochem Bio. 1984:21: 130-32.

13. Ohkawa H, Ohishi N, Yagi K. Assar for lipid peroxides in animal tissues by thiobarbituric acid reaction. $J$ Anal Biochem. 1979; 351-58.

14. Aebi $H$. Catalase in vitro. Methods in enzymology. 1984; 105:121-126.

15. Moron MS, Depierre JW, Mannervik B. Levels of glutathione reductase and glutathione S-transferase in rat lung and liver.BiochemBiophysic Acta 1979; 582:678.

16. Mohammad SK and R Hentges. Association between tumor necrosis factor-a and disease progression in patients with multiple sclerosis. New England Journal of Medicine. 1991; 325(7):467-472.

17. Witko-Sarsat V, Friedlander $M$, Nguyen $K T$, et al. Advanced oxidation protein products as novel mediators of inflammation and monocyte activation in chronic renal failure. J Immunol. 1998; 161:252432.

18. Bredt, D.S. and Snyder, S.H. Nitric oxide: A physiologic messenger molecule. Annu. Rev. Biochem. 1994:63,175-95.Corm S, Berthon C, Imbenotte M, Biggio V, Lhermitte M, Dupont C, Briche I, Quesnel B.Indoleamine 2,3-dioxygenase activity of acute myeloid leukemia cells can be measured from patients' sera by HPLC and is inducible by IFNgamma. Leuk. Res. 2009; 33:490-494.

19. David $M$ and JS Richard. Glutathione reductase. Methods of enzymatic analysis. 1983; 3:258-265.

20. Seita J, Weissman IL. Hematopoietic Stem Cell: Selfrenewal versus Differentiation. Wiley interdisciplinary reviews Systems biology and medicine. 2010; 2(6):640653.

21. Ott M, Gogvadze V, Orrenius S and Zhivotovsky B. Mitochondria, oxidative stress and cell death. Apoptosis. 2007; 12:913-922.

22. Al-Gayyar MM, Eissa LA, Rabie AM, El-Gayar AM. Measurements of oxidative stress status and antioxidant activity in chronic leukaemia patients. J Pharm Pharmacol. 2007; 59:409-417.

23. He YL, Cao LZ, Yang J, Yang $M H$, Xu WQ, Xie $M$ and Shi Z. Expression of WAVE1 and p22phox in children with acute lymphocytic leukemia and the relationship of WAVE1 with oxidative stress. Zhongguo Dang Dai Er Ke Za Zhi. 2009; 11:88-92.

24. Battisti V, Maders LD, Bagatini MD, Santos KF, Spanevello RM, Maldonado PA, Brulé AO, Araújo Mdo C, Schetinger MR and Morsch VM. Measurement of oxidative stress and antioxidant status in acute lymphoblastic leukemia patients. Clin. Biochem. 2008; 41:511-518.

25. Mazor D, Abucoider A, Meyerstein N, Kapelushnik J. Antioxidant status in pediatric acute lymphocytic leukemia (ALL) and solid tumors: The impact of oxidative stress. Pediatr. Blood Cancer. 2008; 51:613615.

26. Zhou FL, Zhang WG, Wei YC, Meng S, Bai GG, Wang BY, Yang $\mathrm{HY}$, Tian W, Meng $X$ and Zhang $H$. Involvement of oxidative stress in the relapse of acute myeloid leukemia. J. Biol. Chem. 2010; 285:15010-15015.

27. Furuya $R$, Kumagai $H$, Odamaki $M$, Takahashi $M$, Miyaki $A$, Hishida $A$. Impact of residual renal function 
on plasma levels of advanced oxidation protein products and pentosidine in peritoneal dialysis patients. Nephron Clinical Practice. 2009; 112(4):c255c261.

28. Gangemi M, Seneca V, Colella G, Cioffi V, Imperato $A$, Maiuri $F$. Endoscopy versus microsurgical cyst excision and shunting for treating intracranial arachoid cysts. J Neurosurg Pediatr. 2011;8: 158-164.

29. Dalle-Donne I, Rossi R, Colombo R, Giustarini D, Milazani A. Biomarkers of oxidative stress in human disease. Clin Chem 2006; 52:601-23.

30. Cerutti PA. Oxy-radicals and cancer. Lancet 1994; 344: 862-3.

31. Ghalaut VS, Ghalaut PS, Singh S. Lipid peroxidation in leukemia. J Asso Phys Ind 1999; 47:403-5.

32. Singh V, Ghalaut PS, Kharb S, Singh GP. Plasma concentrations of lipid peroxidation products in children with acute leukemia. Ind J Med Sci 2001; 55: 215-17.

33. Pignatelli B, Li CQ, Boffetta P, Chen Q, Ahrens W, Nyberg $F$, et al. Nitrated and oxidized protein in smokers and lung cancer patients. Cancer Research. 2001; 61(2): 778-84.

34. Morabito F, Cristani M, Saija A, Stelitano C, Callea $V$, Tomaino $A$, et al. Lipid peroxidation and protein oxidation in patients affected by Hodgkin's lymphoma. Mediators Inflam 2004; 13(5-6): 381-3.
35. Sattler M, Verma S, Shrikhande G, Byrne $\mathrm{CH}$, Pride YB, Winkler T, et al. The BCR/ABL tryrosine kinase induces production of reactive oxygen species in hematopoietic cells. J Biol Chem 2000; 275:24273-8.

36. Kurzrock R, Kantarjian HM, Drucker BJ, Talpaz M. Philadelphia chromosome-positive leukemias: From basic mechanisms to molecular therapeutics. Ann Intern Med 2003; 138: 819-30.

37. Koptyra M, Falinski R, Nowicki M, Stoklosa T, Majsterek I, Nieborowska-Skorska M, Blasiak J, Skorski T. BCR/ $A B L$ kinase induces self-mutagenesis via reactive oxygen species to encode imatinib resistance. Blood 2006; 108(1): 319-27.

38. Termini J. Hydroperoxide induced DNA damage and mutations. Mutat. Res. 2000; 450:107-124.

39. Oltra AM, Carbonell F, Tormos C, Iradi A, and Saez GT. Antioxidant enzyme activities and the production of MDA and 8-oxo-dG in chronic lymphocytic leukemia. Free Radical Biology \& Medicine. 2001; vol. 30, no. 11, pp. 1286-1292.

40. Xian J, Shao H, Chen X, Zhang S, Quan J, Zou Q, Jin $H$, and Zhang $L$. Nucleophosmin mutants promotes adhesion, migration and invasion of human leukemia THP-1 cells through MMPs up-regulation via Ras/ ERK MAPK signaling. Int J. Biol Sci. 2016; 12(2):144155.

41. Michael S, et al. Role of leukemia cell invadosome in extramedullary infiltration. Blood. 2009; 114(4):30083017.

\section{AUTHORSHIP AND CONTRIBUTION DECLARATION}

\begin{tabular}{|c|l|l|}
\hline Sr. \# & \multicolumn{1}{|c|}{ Author-s Full Name } & \multicolumn{1}{|c|}{ Contribution to the paper } \\
\hline 1 & Muhammad Shahzad Farooq & Writing Editing \\
\hline 2 & Arif Malik & Complications \\
3 & Bushra Shaheen & Editing, Reading \\
4 & Qurat-ul-Ain & Reviewing \\
5 & Sulayman Waquar & Methodology Reviewing
\end{tabular}

